\title{
Perception of impairments by patients with heart failure.
}

I H Kraai, K M Vermeulen, H L Hillege and Tiny Jaarsma

\author{
Linköping University Post Print
}

\section{Tweet}

N.B.: When citing this work, cite the original article.

Original Publication:

I H Kraai, K M Vermeulen, H L Hillege and Tiny Jaarsma, Perception of impairments by patients with heart failure., 2016, European Journal of Cardiovascular Nursing, (15), 2, 178185.

http://dx.doi.org/10.1177/1474515115621194

Copyright: Elsevier / SAGE Publications (UK and US): 12 month Embargo

http://www.uk.sagepub.com/home.nav

Postprint available at: Linköping University Electronic Press

http://urn.kb.se/resolve?urn=urn:nbn:se:liu:diva-125915

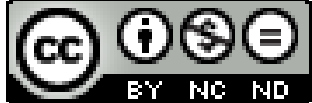




\section{PERCEPTION OF IMPAIRMENTS BY PATIENTS WITH HEART FAILURE}

Kraai, I.H., MSc ${ }^{\mathrm{a}}$; Vermeulen, K.M., PhD ${ }^{\mathrm{b}}$; Hillege, H.L., PhD ${ }^{\mathrm{a} ;}$ Jaarsma, T., $\mathrm{PhD}^{\mathrm{c}}$

${ }^{a}$ Department of Cardiology, University Medical Center Groningen, University of Groningen, the Netherlands.

b Department of Epidemiology, University Medical Center Groningen, University of Groningen, the Netherlands

${ }^{\mathrm{c}}$ Department of Social and Welfare Studies, Faculty of Health Sciences Linköping University, Linköping, Sweden

Corresponding author:

I.H. Kraai, MSc

University of Groningen, University Medical Center Groningen,

Department of Cardiology, HPC AB 41

Postbox 30.001

9700 RB Groningen

The Netherlands

Email: i.h.kraai@umcg.nl

Phone: +31 503611747

Fax: +31 503618062 


\section{ABSTRACT}

Background: One of the major treatment aims in heart failure (HF) is symptom relief and improvement of health-related quality of life (HR-QoL). The perception of impairments due to HF may differ between patients. In order to provide personalized care on a patient level, to optimize care on a population level and to find the most appropriate patient reported outcome for clinical trials, knowledge regarding prevalence and perceived harshness of impairments due to HF is essential.

Aim: The aim of this study was to explore the prevalence and perceived harshness of impairments due to HF and the relation between perceived harshness and HR-QoL in HFpatients.

Methods and results: Prevalence of impairments due to HF was assessed with items of the Minnesota Living with Heart Failure Questionnaire (MLHFQ) and degree of perceived harshness was assessed with structured self-assessment. A total of 100 outpatients (mean age $70 \pm 9$ years, $71 \%$ male) from the HF-clinic were included. Prevalence of impairments ranged between $18-77 \%$. The most prevalent impairments includes tiredness and physical activity impairments. Impairments that were frequently perceived as severely harsh included tiredness (67\%), dyspnea (57\%) and physical activity impairments (55\%). Corrected item-total correlation (range 0.10-0.59) showed that tiredness $(\mathrm{r}=0.54)$ and impairments related to resting $(r=0.59)$ and to participation in physical activities $(r=0.52)$ and social activities $(\mathrm{r}=0.55)$ contributed highly to the sum-score of the MLHFQ.

Conclusion: Highly prevalent impairments are not by definition perceived as severely harsh by HF-patients and do not contribute relevantly to the overall HR-QoL except for the impairments tiredness and working around the house/ yard. These insights are important for providing personalized and optimized HF-care.

Keywords: Heart failure, Quality of life, degree of harshness, Severity of impairments 


\section{INTRODUCTION}

Heart failure (HF) is a serious illness with a poor prognosis. ${ }^{1,2}$ In addition to symptom relief and the prevention of hospital admissions, the main goal when treating chronic HF is to improve the health related quality of life (HR-QoL). ${ }^{3}$ Until recently, cardiovascular trials have been primarily oriented at mortality and re-hospitalizations. However, due to recommendations of the US Food and Drug Administration (FDA), the American Heart Association (AHA) and the European Society of Cardiology (ESC) ${ }^{4-7}$ there is an increasing interest in measuring patient-reported outcomes. By using patient-reported outcomes such as HR-QoL in clinical trials, the effect of interventions can be assessed from a patient's perspective, which is particularly useful when interventions are aimed at improving symptoms or functional status. ${ }^{8}$

The key challenge is to understand and find ways to help HF patients live with their disease, ${ }^{9}$ and to improve their HR-QoL. HR-QoL includes elements of physical, functional, emotional, and mental well-being and is a reflection of the way patients perceive and react to their health status. ${ }^{10}$ On a population level, HR-QoL in HF patients is seriously reduced with respect to all these elements when compared both to a normative population ${ }^{11}$ and to patients with other chronic diseases. ${ }^{12}$ Moreover, a reduced HR-QoL is a significant predictor of adverse prognosis in patients with chronic HF. ${ }^{13}$

HR-QoL is described in general terms for a group of patients however on an individual level patients might perceive their health status differently and they may have individual preferences as to what is important in their lives and what they find difficult to cope with. This perception of impairments on an individual level is outlined by the term perceived harshness as described by Rhodes et al. ${ }^{14}$ in a previous study and adopted in this study. The perceived harshness of an impairment is described as the degree of discomfort patients experience with respect to this impairment: no discomfort, moderate discomfort, or severe 
discomfort and is reported directly by the patient. Other symptom measurements such as the New York Heart Association (NYHA) classification are reported by the physician after the interpretation of the symptoms of the patient. It is important to have good knowledge on prevalence and degree of perceived harshness of impairments due to HF which is reported directly by the patient to provide and improve personalized care on a patient level, to optimize care on a population level, and to identify the most appropriate patient-reported outcomes for clinical trials. This is particularly useful when interventions are aimed to improve symptoms or functional status. Therefore, the aims of this study are (1) to explore the prevalence of impairments due to HF in general and in patients with different NYHA classifications, (2) to explore the degree of perceived harshness regarding impairments due to HF, and (3) to describe how the perceived degree of harshness regarding the separate impairments relates to the overall HR-QoL.

\section{METHODS}

\section{Participants}

This descriptive study used a cross-sectional design, and data were collected during a larger study on the preferences of HF patients regarding quality of life versus longevity in daily clinical practice. ${ }^{15}$ In total, 159 patients enrolled at the HF clinic of the University Medical Center Groningen in the Netherlands between January and July 2012 were asked to participate in the study. Fifty-six patients declined. Inclusion criteria were as follows: diagnosis of HF, NYHA classification I-IV, and age 50 years or older. Exclusion criteria were having impaired cognition or not being able to understand informed consent as determined by the HF nurse or having insufficient knowledge of the Dutch language; 56 patients refused to participate in the study, 30 patients did not want to give a specific reason for not taking part in the study. Other 
reasons for not taking part in the study were not willing to invest the time, tiredness, family is waiting, visual impairments and wanting to go home because of an ill partner. The study activities were performed by independent researchers and were combined with routine visits to the HF outpatient clinic. Our study conforms with the principles outlined in the Declaration of Helsinki. ${ }^{16}$ The medical ethics committee approved the study protocol, and all included patients provided their written informed consent.

\section{Measurements}

\section{Prevalence and degree of perceived harshness regarding impairments due to HF}

The prevalence of impairments due to HF was assessed with the Minnesota Living with Heart Failure Questionnaire (MLHFQ). The content of the MLHFQ targets those impairments that patients frequently attribute to their heart failure ${ }^{17}$ and addresses physical, social, emotional, dietary, and economic limitations, as well as the side-effects of treatment. ${ }^{18}$ The MLHFQ contains 21 items and scores range from 0 (not affected) to 5 (very much affected). An impairment was considered to be prevalent if the related item scored between 1 and 5 .

In this study, the level of perceived harshness of an impairment was defined as the degree of discomfort patients experienced with respect to this particular impairment: no discomfort, moderate discomfort, or severe discomfort. ${ }^{14}$ The degree of perceived harshness of impairments caused by HF was assessed with a method that was specifically developed for this study. The MLHFQ items were rephrased and written on separate cards. Examples of rephrased questions include: 'how difficult is it for you to suffer from swollen ankles or legs?' or 'how difficult is it for you to sit or lie down to rest during the day?'. Patients were then asked to assign the question card to the category that fit their degree of perceived harshness of the impairment best. They could choose from 'no discomfort', 'moderate discomfort' or 
'severe discomfort'. If a patient answered that the described impairment was not present or inapplicable, this was registered as well.

Both instruments were administrated by trained researchers, who were not involved in the treatment of the included patients. The data was collected during a larger study and the total amount of time required from the patient to complete all the assessments was approximately 45 minutes.

\section{Background characteristics}

Demographic data (age, gender, education) and clinical data (NYHA classification, medical history and laboratory results) were collected from interviews with the patients and from the patients' medical chart. The study activities were combined with routine visits to the HF outpatient clinic during that visit the NYHA classification was assessed and laboratory tests were taken. In incidental cases the laboratory tests were taken several weeks before or after the regular outpatient clinic visit. In these incidental cases the patients were stable regarding their HF and therefore the delay in laboratory tests was not assumed to interfere with the results.

\section{Statistical analyses}

Patient characteristics, clinical outcomes, prevalence and degree of perceived harshness were described using means $( \pm \mathrm{SD}$ ) or median (minimum-maximum) for continuous variables and percentages and numbers for categorical variables. The relation of the perceived degree of harshness of the separate impairments to the overall HR-QoL was assessed with an item-total correlation and a linear regression analysis. The item-total correlation was used to assess the separate contribution of each item to the calculated sum-score of the original MLHFQ and to detect which items of the original MLHFQ correlated with the degree of harshness. Items with 
a correlation that was higher than 0.3 were considered to contribute relevantly to the sumscore of the original MLHFQ. Items with a correlation less than 0.3 did not contribute relevantly with the sum-score. In the linear regression analyses, the sum-score of the original MLHFQ was the dependent variable, and the degree of harshness and the prevalence of an item were the predictor variables. The item by item correlation between the MLHFQ and the level of harshness was performed with the Spearman's rho test. Outcomes with a p value of 0.05 or lower were considered statistically significant. Statistical analyses were performed using IBM SPSS Statistics version 20.0.0.1 for Windows.

\section{RESULTS}

\section{Study population}

A total of 100 patients were included in this study. Their mean age was $70( \pm 9.4)$ years, and $71 \%$ were male (Table 1). In total, $28 \%$ of the patients lived alone and $87 \%$ were retired. Most patients were classified as NYHA class II (53\%) and NYHA class III (34\%). Twentynine of the patients had been admitted to the hospital in the past six months. As for comorbidities, $24 \%$ of the patients were diagnosed with chronic obstructive pulmonary disease, $30 \%$ with diabetes, and $11 \%$ with a stroke.

\section{The prevalence of impairments due to HF}

The prevalence of impairments due to HF ranged between $18-77 \%$ in the study population (Table 2). The most prevalent impairments included tiredness (77\%) and physical activity impairments such as having difficulty working around the house or yard (73\%) and walking or climbing stairs (70\%). The least prevalent impairment due to HF was hospitalization (18\%). 
The prevalence of impairments differed between patients with different NYHA classifications (Figure 1). The three most prevalent impairments reported by patients with NYHA class I ( $\mathrm{n}=11)$ were having difficulty engaging in recreational pastimes such as hobbies or sports $(73 \%, n=8)$, side-effects of treatments $(73 \%, n=8)$, and having difficulty concentrating/ remembering things $(64 \%, n=7)$. In NYHA class II $(n=53)$, the most prevalent impairments were tiredness $(76 \%, n=40)$, having difficulty working around the house or yard $(68 \%, n=36)$, and having to rest during the day $(68 \%, n=36)$. In NYHA class III $(n=34)$, physical activity impairments such as having difficulty walking or climbing stairs (88\%, $\mathrm{n}=30$ ), or having difficulty working around the house or yard $(85 \%, \mathrm{n}=29)$ were most prevalent, together with tiredness $(85 \%, n=29)$.

\section{The degree of perceived harshness regarding impairments due to HF}

Impairments that were perceived most often as severely harsh were tiredness (67\%) and dyspnea (57\%) (Table 2). The impairments related to side-effects of treatment (58\%) and to the performance of physical activities during, for example, recreational pastime (54\%), were most often perceived as moderately harsh. The impairments perceived as least harsh were health care costs (40\%) and being a burden to family or friends (36\%).

\section{Relation between perceived harshness regarding impairments with HR-QoL}

The item-total correlation (r range 0.10-0.59) showed that the degree of perceived harshness of impairments regarding resting $(\mathrm{r}=0.59)$, participation in social activities with family/ friends $(\mathrm{r}=0.55)$, and tiredness $(\mathrm{r}=0.54)$ substantially contributed to the sum-score of the original MLHFQ (Table 2). Impairments related to side-effects of treatments ( $\mathrm{r}=0.20)$, edema in ankles or legs $(\mathrm{r}=0.10)$, and working to earn a living $(\mathrm{r}=0.10)$ moderately contributed to the total score. 
Linear regression analyses showed a significant relation between two impairments perceived as severely harsh and a lower HR-QoL; having to rest during the day $(\mathrm{B}=26.7 ; \mathrm{p}<$ $0.001)$ and having difficulty working around the house/ yard $(\mathrm{B}=22.6$; $\mathrm{p}<0.001)$. The explained variance of both impairments accounted for $44 \%$ of the variation in the sum-score of the original MLHFQ. The linear regression also showed a significant relation between the impairment costs for medical care perceived as severely harsh and a higher HR-QoL $(\mathrm{B}=-$ 14.9; $\left.\mathrm{p}=0.04 ; \mathrm{R}^{2}=19 \%\right)$.

The item by item correlation between the MLHFQ and the level of harshness showed a significant relation for the following impairments: difficulties working around the house or yard $(p<0.0 .1)$, shortness of breath $(p<0.01)$ and suffering from side-effects of treatments $(p=0.05)$. The impairments having to rest during the day $(p=0.06)$ and feeling tired $(p=0.08)$ seemed to be related with the level of harshness through the relation was not statistically significant (Table 3).

\section{DISCUSSION}

This study provides a detailed insight into how patients with HF perceive impairments related to their affliction. To our knowledge, this is the first study to measure the concept of harshness of impairments in this particular group of patients. Interestingly, impairments which were perceived as severely harsh were not by definition the most prevalent impairments in our study population. The item-total correlation of the perceived degree of harshness of impairments to the sum-score of the original MLHFQ showed that some of the highly prevalent impairments did not relevantly contribute to the sum-score of the original MLHFQ. This indicates that it is important for healthcare providers to identify those impairments which are less prevalent, and to discuss those impairments with their patients in addition to 
discussing the more classical HR-QoL items because the less prevalent impairments were often perceived by the patients as causing severe discomfort. Furthermore, the impairments 'having difficulty working to earn a living' and 'swelling in ankles or legs' had a very low contribution to the sum score of the original MLHFQ which can be caused by the fact that most of the patients were retired and during the interview described that they did not mind about the swelling in legs and ankles. We have not a concise explanation for the low contribution to the sum score of the original MLHFQ of the items 'suffering from side effects from treatments' and 'difficulties with concentrating/ remembering things'. These insights into the prevalence and degree of harshness of impairments due to HF can be used to find the most appropriate patient-reported outcome measurements for clinical trials as well.

The prevalence of impairments differed between patients in the different NYHA classes. Since HF has many detrimental physical and psychosocial consequences ${ }^{19}$, having good knowledge of impairments experienced by patients in different NYHA classes is highly useful to HF nurses during follow-up. Patients in NYHA class I, for example, frequently reported impairments that were hindering their engagement in recreational pastimes or that were caused by side-effects of treatments. Side-effects of treatment might endanger adherence to treatment and could even lead to hospitalization. ${ }^{20}$ Furthermore, it is necessary for a HF patient to engage in regular aerobic exercise so as to maintain a good physical condition, to improve functional capacity, and to improve symptoms. ${ }^{3,21}$ When a patient experiences severe discomfort while engaging in aerobic exercise, HF nurses need to be aware of this impairment. They also need to educate patients on the importance of treatment recommendations and discuss strategies that will help keep their patients motivated to follow through with treatment plans. ${ }^{3}$ In NYHA class II and III, the most prevalent impairments were tiredness and physical activity impairments. In NYHA class III, physical activity impairments such as having difficulty walking and climbing stairs were most prevalent. The ability to 
perform activities of daily living and to move around, as well as to have enough energy to perform these activities are considered to be important aspects of HR-QoL, particularly in older adults. ${ }^{22,}{ }^{23}$ Improving patients' physical capacity to perform these activities can be established gradually with a mobilization program that uses a variety of simple movements, even in patients with severe HF. Furthermore, cardiac rehabilitation can reduce feelings of fatigue. ${ }^{21}$ Reduced energy or tiredness is a typical HF impairment ${ }^{3}$ which patients not only experience as debilitating and demoralizing, ${ }^{9}$ but which also has substantial consequences for everyday life. ${ }^{24}$ Patient-tailored interventions aimed at specific problems and beliefs might help patients in the different NYHA classes to implement the HF regimen in their daily lives, ${ }^{25}$ to cope with their impairments and to improve their HR-QoL.

Contrary to previous studies ${ }^{26,27}$ in which chronic illness led to family burden and increase in social isolation, the prevalence and degree of harshness of feeling a burden to family or friends in our study population was relatively low, as was the prevalence of impairments related to doing things with family or friends. Patients reported that they had helped their family (i.e., sons and daughters) all their lives and that now their family was able to give something back. We did not ask the family members about their feelings, it is therefore possible that the family of the included patients will have another opinion about this. Research regarding family burden is needed both from the perspectives of the patient and family. The prevalence of the impairment healthcare costs was low as well, which can be explained by the fact that the Dutch health insurance system reimburses the majority of healthcare costs. The expenses mentioned by the study population included expenses regarding parking fees, fuel costs, and their own financial contribution to the insurance. Notable is the relation between perceiving the healthcare costs as severely harsh and a higher overall HR-QoL. 
One limitation of our study is that we used an alternative method to obtain more information regarding the degree of harshness of impairments perceived by HF patients. This method has not been validated yet because our study was merely performed for descriptive purpose. Therefore, more research is needed on the perception of impairments by HF patients, and our results need to be confirmed by other studies. Furthermore, it was not surprising that perceived harshness was found to be correlated with the MLHFQ given that the original questionnaire also contains a measure of severity in terms of degree affected by an individual component. However, we would recommend to continue the development of the MLHFQ to include this harshness component. Another limitation is that we did not add other variables to the linear regression such as age and gender to correct for confounders because this was not the aim of our study, more research is needed regarding this. Another issue that should be further studied is that patients with HF frequently experience high levels of fear in their lives. ${ }^{9}$ An item that addresses fear-related impairments could be added to further develop this adapted questionnaire.

\section{Conclusion}

This study has shown that the most prevalent impairments caused by HF are not by definition the impairments which HF patients themselves perceive as severely harsh except for the impairments tiredness and working around the house/ yard. Several of the items with more severe perceived degree of harshness are also the most prevalent. As a result, highly prevalent impairments do not contribute relevantly to the overall HR-QoL for this group of HF patients except for the impairments tiredness and working around the house/ yard. Therefore, it is important for healthcare providers to discuss less prevalent impairments with their patients. Moreover, by using an adapted version of a frequently used HR-QoL instrument in HF patients, this study has provided a detailed exploration of the perception of impairments by 
patients with HF. Insights into the prevalence and perceived degree of harshness of impairments due to HF are important with respect to providing personalized care on a patient level, optimizing care on a population level, and finding the most appropriate patient-reported outcomes for clinical trials. However, more research into the perception of patients regarding impairments caused by HF is needed to create a well-developed instrument that can be used in clinical trials.

\section{Acknowledgements}

This work was supported by the Dutch Ministry of Health, Welfare, and Sport.

\section{Conflict of interest:}

None declared 


\section{REFERENCES}

1. Stewart S, MacIntyre K, Hole DJ, et al. More 'malignant' than cancer? Five-year survival following a first admission for heart failure. Eur J Heart Fail 2001; 3: 315-322.

2. Mosterd A and Hoes AW. Clinical epidemiology of heart failure. Heart 2007; 93: 11371146.

3. McMurray JJ, Adamopoulos S, Anker SD, et al. ESC guidelines for the diagnosis and treatment of acute and chronic heart failure 2012: The Task Force for the Diagnosis and Treatment of Acute and Chronic Heart Failure 2012 of the European Society of Cardiology. Developed in collaboration with the Heart Failure Association (HFA) of the ESC. Eur J Heart Fail 2012; 14: 803-869.

4. Rumsfeld JS, Alexander KP, Goff DC,Jr, et al. Cardiovascular health: the importance of measuring patient-reported health status: a scientific statement from the american heart association. Circulation 2013; 127: 2233-2249.

5. Zannad F, Garcia AA, Anker SD, et al. Clinical outcome endpoints in heart failure trials: a European Society of Cardiology Heart Failure Association consensus document. Eur J Heart Fail 2013; 15: 1082-1094.

6. Anker SD, Agewall S, Borggrefe M, et al. The importance of patient-reported outcomes: a call for their comprehensive integration in cardiovascular clinical trials. Eur Heart J 2014; 35: 2001-2009. 
7. US department of Health and Human Services Food and Drug Administration. Guidance for industry: patient-reported outcome measures: use in medical product development to support labelling claims, http://www.fda.gov/downloads/Drugs/GuidanceComplianceRegulatoryInformation/Guidance s/UCM193282.pdf (2009, accessed September 29 2010).

8. Rahimi K, Malhotra A, Banning AP, et al. Outcome selection and role of patient reported outcomes in contemporary cardiovascular trials: systematic review. BMJ 2010; 341: c5707.

9. Ryan M and Farrelly M. Living with an unfixable heart: a qualitative study exploring the experience of living with advanced heart failure. Eur J Cardiovasc Nurs 2009; 8: 223-231.

10. Gill TM and Feinstein AR. A critical appraisal of the quality of quality-of-life measurements. JAMA 1994; 272: 619-626.

11. Lesman-Leegte I, Jaarsma T, Coyne JC, et al. Quality of life and depressive symptoms in the elderly: a comparison between patients with heart failure and age- and gender-matched community controls. J Card Fail 2009; 15: 17-23.

12. Juenger J, Schellberg D, Kraemer S, et al. Health related quality of life in patients with congestive heart failure: comparison with other chronic diseases and relation to functional variables. Heart 2002; 87: 235-241. 
13. Mommersteeg PM, Denollet J, Spertus JA, et al. Health status as a risk factor in cardiovascular disease: a systematic review of current evidence. Am Heart J 2009; 157: 208218.

14. Rhodes VA and Watson PM. Symptom distress--the concept: past and present. Semin Oncol Nurs 1987; 3: 242-247.

15. Kraai IH, Vermeulen KM, Luttik ML, et al. Preferences of heart failure patients in daily clinical practice: quality of life or longevity?. Eur J Heart Fail 2013; 15: 113-1121.

16. RICKHAM PP. Human Experimentation. Code of Ethics of the World Medical Association. Declaration of Helsinki. Br Med J 1964; 2: 177.

17. Rector TS and Cohn JN. Assessment of patient outcome with the Minnesota Living with Heart Failure questionnaire: reliability and validity during a randomized, double-blind, placebo-controlled trial of pimobendan. Pimobendan Multicenter Research Group. Am Heart J 1992; 124: 1017-1025.

18. Rector TS, Tschumperlin LK, Kubo SH, et al. Use of the Living With Heart Failure questionnaire to ascertain patients' perspectives on improvement in quality of life versus risk of drug-induced death. J Card Fail 1995; 1: 201-206.

19. Yu DS, Lee DT, Kwong AN, et al. Living with chronic heart failure: a review of qualitative studies of older people. J Adv Nurs 2008; 61: 474-483. 
20. Mockler M, O'Loughlin C, Murphy N, et al. Causes and consequences of nonpersistence with heart failure medication. Am J Cardiol 2009; 103: 834-838.

21. Piepoli MF, Conraads V, Corra U, et al. Exercise training in heart failure: from theory to practice. A consensus document of the Heart Failure Association and the European Association for Cardiovascular Prevention and Rehabilitation. Eur J Heart Fail 2011; 13: 347357.

22. Molzahn A, Skevington SM, Kalfoss M, et al. The importance of facets of quality of life to older adults: an international investigation. Qual Life Res 2010; 19: 293-298.

23. Austin J, Williams WR and Hutchison S. Patterns of fatigue in elderly heart failure patients measured by a quality of life scale (Minnesota living with heart failure). Eur J Cardiovasc Nurs 2012; 11: 439-444.

24. Hagglund L, Boman K and Lundman B. The experience of fatigue among elderly women with chronic heart failure. Eur J Cardiovasc Nurs 2008; 7: 290-295.

25. van der Wal MH, Jaarsma T, Moser DK, et al. Qualitative examination of compliance in heart failure patients in The Netherlands. Heart Lung 2010; 39: 121-130.

26. Sales E. Family burden and quality of life. Qual Life Res 2003; 12 Suppl 1: 33-41.

27. Fitzsimons D, Mullan D, Wilson JS, et al. The challenge of patients' unmet palliative care needs in the final stages of chronic illness. Palliat Med 2007; 21: 313-322. 
Table 1. Demographic and clinical characteristics of the total HF population $(n=100)$.

\begin{tabular}{|c|c|}
\hline Demographics & \\
\hline Age (years) & $70( \pm 9,4)$ \\
\hline Gender (female) & $29 \%$ \\
\hline Living alone & $28 \%$ \\
\hline Having children & $88 \%$ \\
\hline Education level: & \\
\hline No education/ primary school & $38 \%$ \\
\hline Diploma secondary school & $45 \%$ \\
\hline Higher education/ university & $17 \%$ \\
\hline Work position: Fulltime/ part-time work & $13 \%$ \\
\hline Being Religious & $43 \%$ \\
\hline Clinical characteristics & \\
\hline LVEF \% & $33( \pm 12)$ \\
\hline NYHA: I & $11 \%$ \\
\hline II & $53 \%$ \\
\hline III & $34 \%$ \\
\hline IV & $2 \%$ \\
\hline Laboratory : Hemoglobin (mmol/l) & $8.6( \pm 1.1)$ \\
\hline eGFR (ml/min*1.73m2) & $54( \pm 20)$ \\
\hline NT-pro-BNP (ug/l) & $1222(79-216327)$ \\
\hline Ischemic heart failure & $55 \%$ \\
\hline ICD implantation & $42 \%$ \\
\hline Resuscitation in the past & $10 \%$ \\
\hline Myocardial infarction & $50 \%$ \\
\hline
\end{tabular}




\begin{tabular}{cc}
\hline Duration of HF (years) & $2.7( \pm 3.6)$ \\
\hline HF readmission in last 6 months & $29 \%$ \\
\hline Co-morbidities: COPD & $24 \%$ \\
\hline Diabetes Mellitus & $30 \%$ \\
\hline Stroke & $11 \%$ \\
\hline Hypertension & $57 \%$ \\
\hline Cancer & $20 \%$ \\
\hline
\end{tabular}

Note:

Mean $( \pm \mathrm{SD})$, percentage (number) or median (minimum-maximum)

HF = heart failure; LVEF = left ventricular ejection fraction; NYHA = New York Heart

Association; eGFR = estimated globular filtration rate; NT-pro-BNP = N-terminal

prohormone of brain natriuretic peptide; ICD = internal cardiac defibrillator; COPD = Chronic obstructive pulmonary disease. 
Table 2: The prevalence and perceived degree of harshness regarding impairments due to HF $(n=100)$

\begin{tabular}{|c|c|c|c|c|c|}
\hline $\begin{array}{l}\text { Item MLHFQ } \\
\text { (number: description item) }\end{array}$ & Prevalence & $\begin{array}{l}\text { No perceived } \\
\text { harshness }\end{array}$ & $\begin{array}{l}\text { Moderate degree } \\
\text { of perceived } \\
\text { harshness }\end{array}$ & $\begin{array}{l}\text { Severe degree of } \\
\text { perceived } \\
\text { harshness }\end{array}$ & $\begin{array}{l}\text { Corrected item-total } \\
\text { correlation (r) }\end{array}$ \\
\hline 13: feeling tired, fatigued, or low on energy & $77 \%$ & $4 \%(4)$ & $29 \%(26)$ & $67 \%(60)$ & 0.54 \\
\hline $\begin{array}{l}\text { 3: having difficulty walking about or climbing } \\
\text { stairs }\end{array}$ & $70 \%$ & $8 \%(7)$ & $37 \%(31)$ & $55 \%(46)$ & 0.30 \\
\hline $\begin{array}{l}\text { 9: having difficulty engaging in recreational } \\
\text { pastimes/sports/ hobbies }\end{array}$ & $63 \%$ & $16 \%(12)$ & $54 \%(39)$ & $30 \%(22)$ & 0.38 \\
\hline 19: worrying & $59 \%$ & $20 \%(15)$ & $50 \%(37)$ & $30 \%(22)$ & 0.34 \\
\hline 11: eating less of the foods you like & $56 \%$ & $22 \%(18)$ & $51 \%(41)$ & $27 \%(22)$ & 0.37 \\
\hline 18: feeling a loss of self-control in life & $56 \%$ & $13 \%(10)$ & $45 \%(35)$ & $42 \%(32)$ & 0.31 \\
\hline
\end{tabular}




\begin{tabular}{|c|c|c|c|c|c|}
\hline $\begin{array}{l}\text { 20: having difficulty concentrating/ } \\
\text { remembering things }\end{array}$ & $51 \%$ & $19 \%(11)$ & $47 \%(28)$ & $34 \%(20)$ & 0.27 \\
\hline 16: suffering from side-effects from treatments & $51 \%$ & $12 \%(9)$ & $58 \%(42)$ & $30 \%(22)$ & 0.20 \\
\hline $\begin{array}{l}\text { 10: having difficulty engaging in sexual } \\
\text { activities }\end{array}$ & $47 \%$ & $13 \%(8)$ & $43 \%(27)$ & $44 \%(28)$ & 0.31 \\
\hline 15: money costs for medical care & $42 \%$ & $40 \%(31)$ & $43 \%(34)$ & $17 \%(13)$ & 0.40 \\
\hline 6: having sleeping problems at night & $41 \%$ & $13 \%(7)$ & $34 \%(19)$ & $53 \%(29)$ & 0.34 \\
\hline 21: feeling depressed & $39 \%$ & $14 \%(7)$ & $47 \%(23)$ & $39 \%(19)$ & 0.37 \\
\hline $\begin{array}{l}\text { 5: making going places away from home } \\
\text { difficult }\end{array}$ & $35 \%$ & $16 \%(7)$ & $45 \%(20)$ & $39 \%(17)$ & 0.38 \\
\hline $\begin{array}{l}\text { 7: having difficulty doing things with friends or } \\
\text { family }\end{array}$ & $32 \%$ & $28 \%(13)$ & $44 \%(20)$ & $28 \%(13)$ & 0.55 \\
\hline 1: causing swelling in ankles or legs & $32 \%$ & $24 \%(16)$ & $43 \%(29)$ & $33 \%(22)$ & 0.10 \\
\hline 17: feeling a burden to family or friends & $26 \%$ & $36 \%(18)$ & $44 \%(22)$ & $20 \%(10)$ & 0.37 \\
\hline 8: having difficulty working to earn a living & $21 \%$ & $7 \%(2)$ & $45 \%(12)$ & $48 \%(13)$ & 0.10 \\
\hline 14: stay in a hospital & $18 \%$ & $35 \%(29)$ & $34 \%(29)$ & $31 \%(26)$ & 0.35 \\
\hline
\end{tabular}


Note:

HF = Heart Failure; MLHFQ = Minnesota Living with Heart Failure Questionnaire

Percentage (number); The accentuated items are most prevalent in that row; Degree of harshness if an MLHFQ item is prevalent

Corrected item-total correlation to assess the correlation between each item and the calculated total sum-score of the original MLHFQ. Items with a correlation higher than 0.3 were considered to have a relevant contribution to the total sum-score of the original MLHFQ. Items with a correlation less than 0.3 do not contribute to the total sum-score of the original MLHFQ. 
Table 3. The correlation of the level of harshness with the MLHFQ item by item $(n=100)$

\begin{tabular}{|c|c|c|}
\hline MLHFQ & Spearman's rho & $p$ \\
\hline 1: causing swelling in ankles or legs & 0.14 & 0.44 \\
\hline 2: having to sit or lie down to rest during the day & 0.23 & 0.06 \\
\hline 3: having difficulty walking about or climbing stairs & 0.17 & 0.16 \\
\hline 4: having difficulty working around the house or yard & 0.31 & 0.009 \\
\hline 5: making going places away from home difficult & 0.05 & 0.76 \\
\hline 6: having sleeping problems at night & 0.21 & 0.19 \\
\hline 7: having difficulty doing things with friends or family & -0.23 & 0.22 \\
\hline 8: having difficulty working to earn a living & 0.14 & 0.56 \\
\hline $\begin{array}{l}\text { 9: having difficulty engaging in recreational } \\
\text { pastimes/sports/ hobbies }\end{array}$ & 0.01 & 0.92 \\
\hline 10: having difficulty engaging in sexual activities & 0.24 & 0.11 \\
\hline 11: eating less of the foods you like & 0.19 & 0.17 \\
\hline 12: short of breath & 0.41 & 0.001 \\
\hline 13: feeling tired, fatigued, or low on energy & 0.20 & 0.08 \\
\hline 14: stay in a hospital & -0.14 & 0.58 \\
\hline 15: money costs for medical care & 0.13 & 0.40 \\
\hline 16: suffering from side-effects from treatments & 0.28 & 0.05 \\
\hline 17: feeling a burden to family or friends & 0.34 & 0.09 \\
\hline 18: feeling a loss of self-control in life & -0.07 & 0.62 \\
\hline 19: worrying & 0.20 & 0.13 \\
\hline 20: having difficulty concentrating/ remembering things & 0.08 & 0.60 \\
\hline 21: feeling depressed & 0.14 & 0.39 \\
\hline
\end{tabular}


Note: MLHFQ = Minnesota Living with Heart Failure Questionnaire. The accentuated items are significant at the 0.01 level. 
Figure 1. Prevalence of impairments in patients with NYHA classification I-III

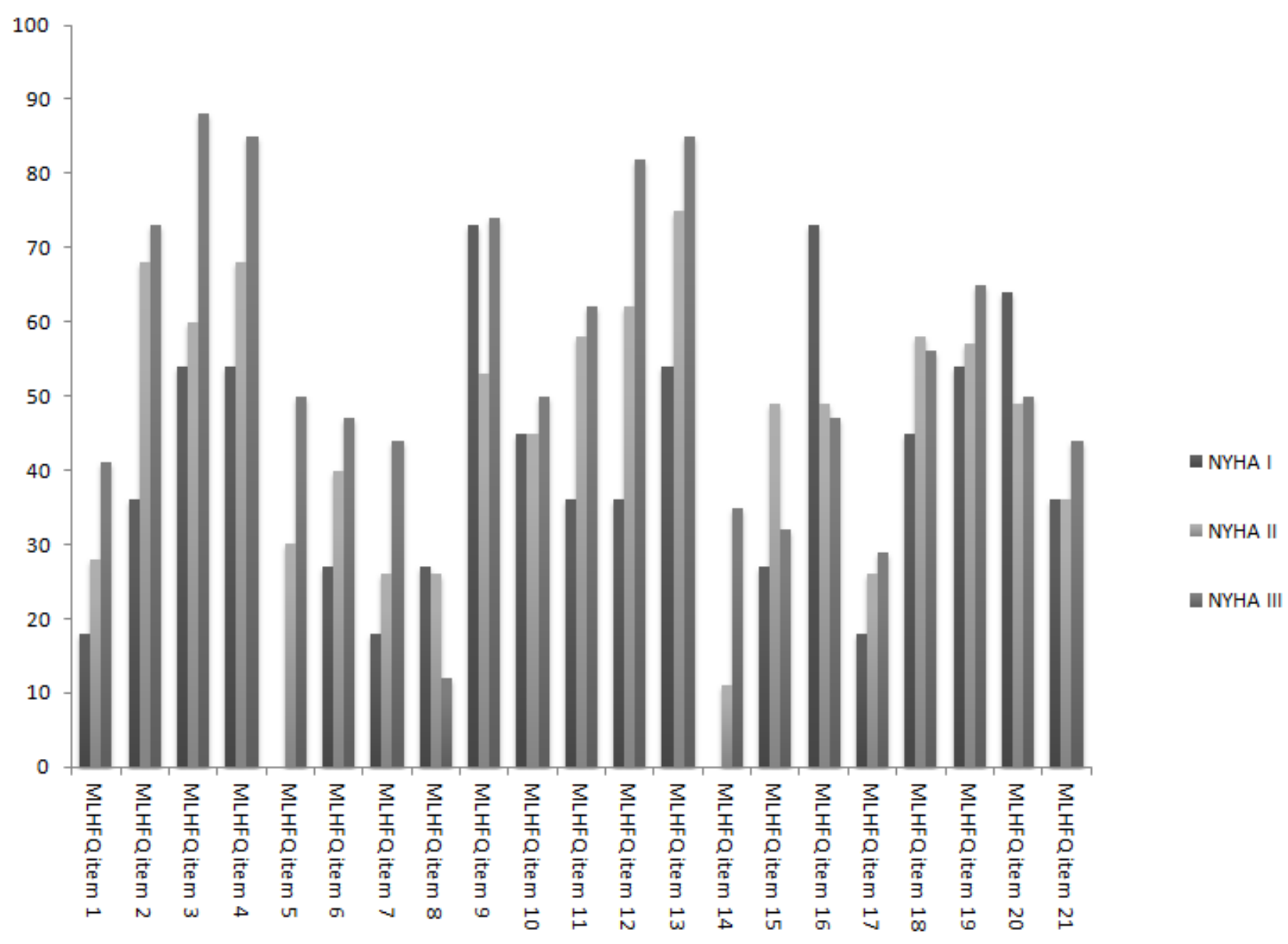

